\title{
Temperamental characteristics in childhood migraine without aura: a multicenter study
}

This article was published in the following Dove Press journal:

Neuropsychiatric Disease and Treatment

13 August 2013

Number of times this article has been viewed

\author{
Maria Esposito' \\ Rosa Marotta ${ }^{2}$ \\ Beatrice Gallai ${ }^{3}$ \\ Lucia Parisi ${ }^{4}$ \\ Giuseppina Patriciello' \\ Serena Marianna Lavano 2 \\ Giovanni Mazzotta ${ }^{5}$ \\ Michele Roccella ${ }^{4}$ \\ Marco Carotenuto' \\ 'Center for Childhood Headache, \\ Clinic of Child and Adolescent \\ Neuropsychiatry, Department \\ of Mental Health, Physical and \\ Preventive Medicine, Second \\ University of Naples, Naples, Italy; \\ 2Department of Psychiatry, "Magna \\ Graecia" University of Catanzaro, \\ Catanzaro, Italy; ${ }^{3}$ Unit of Child \\ and Adolescent Neuropsychiatry, \\ University of Perugia, Perugia, Italy; \\ ${ }^{4}$ Child Neuropsychiatry, Department \\ of Psychology, University of Palermo, \\ Palermo, Italy; ${ }^{5}$ Unit of Child and \\ Adolescent Neuropsychiatry, AUSL \\ Umbria 2, Terni, Italy
}

Correspondence: Beatrice Gallai Unit of Child and Adolescent Neuropsychiatry, University of Perugia, Via Enrico dal Pozzo, 06I00, Perugia, Italy $\mathrm{Tel}+39744204506$

Fax +39744204506

Email beagallai@gmail.com
Background: Children with migraine seem to be more anxious, sensitive, deliberate, cautious, fearful, vulnerable to frustration, tidy, and less physically enduring than comparisons. To the best our knowledge no studies about the temperamental and the characterial dimension aspects in childhood migraine was conducted. Therefore, the aim of the present study was to describe the temperamental and character aspects in a sample of children affected by migraine without aura $(\mathrm{MoA})$ and their relationship with clinical aspects of MoA such as frequency, duration, and severity of attacks.

Materials and methods: In our study, 486 children affected by MoA (239 male, 247 female) aged 7-12 years, (mean $10.04 \pm 2.53$ years) and 518 typical developing children comparable for age $(P=0.227)$ and sex $(P=0.892)$ were enrolled to assess their temperamental characteristics. The mothers of all subjects filled out the Junior Temperament and Character Inventory: Parent Version.

Results: Children affected by migraine show a higher prevalence of harm avoidance and persistence temperamental domains $(P<0.001)$ and significantly lower prevalence of the self-directedness character trait $(P=0.023)$ with respect to the comparisons, according to Cloninger's model. The Spearman rank correlation analysis shows a significant relationship between migraine characteristics and temperamental domains.

Conclusion: The present study first identified differences in temperamental characteristics in children affected by MoA with respect to the comparisons, suggesting the need for this evaluation in order for better psychological pediatric management of children with migraine, with possible consequences and impact on the future outcomes of these subjects.

Keywords: migraine without aura, children, temperament, JTCI

\section{Introduction}

The concept of temperament refers to the early-appearing individual differences in emotional response, and by definition temperament is innate. ${ }^{1}$ On the other hand, in the last several years approaches have been proposed in order to classify an individual's temperamental characteristics, including Cloninger's psychobiological model of the four basic higher order temperament dimensions. ${ }^{2,3}$

According to Cloninger's theory, the temperament features are constitutionally based, partially of genetic origin, and lay the groundwork of the later adult personality. Moreover, the revised psychobiological model includes four temperament dimensions: novelty seeking (NS), harm avoidance (HA), reward dependence (RD), and persistence $(\mathrm{P})$. The three higher order character dispositions, self-directedness (SD), cooperativeness (C), and self-transcendence (ST), refer to differences in attitudes toward 
the self and others, which develop as a result of interactions between temperament and environment. ${ }^{4}$ Summarizing, among the temperament scales, NS was identified for the level of exploratory excitability, impulsivity, and strangeness typical of each individual; HA for the level of anticipatory anxiety, fear of uncertain events, and distrust; RD for the level of attachment and social dependency; and P for differences in the determination and tenacity to achieve a goal in the face of frustration or fatigue. ${ }^{5}$

The characterological aspects of the personality seem to involve individual differences in self-concepts about goals and values, in contrast to the temperaments that involve differences in the automatic emotional reactions and habits. ${ }^{6}$

Accordingly, the three character dimensions are linked to both an intellectual perspective about self/nonself boundaries and to an emotional perspective. In fact, SD is based on the concept of the self as an autonomous individual; from this self-concept are derived feelings of personal integrity, honor, self-esteem, effectiveness, leadership, and hope. Likewise, $\mathrm{C}$ is based on the concept of self as an integral part of humanity or society; from this self-concept are derived feelings of community, compassion, conscience, and charity. Furthermore, ST is based on the concept of self as an integral part of the universe and its source; from this self-concept are derived feelings of mystical participation, religious faith, and unconditional equanimity and patience. ${ }^{7}$

The importance of temperament on mental health ${ }^{3}$ on somatic health ${ }^{8,9}$ has been previously established. Among the somatic complaints, migraine without aura (MoA) could be considered as common in childhood, with a prevalence ranging from $2 \%$ to $17 \% .^{10,11}$

In general, during childhood MoA may not be considered only as a painful syndrome because it is often accompanied by many severe disabilities/impairments, such as low emotional and psychological functioning, ${ }^{12}$ familiar stress, ${ }^{13,14}$ school absenteeism, impairment of academic performance and cognitive functioning, ${ }^{10,15}$ motor coordination, ${ }^{16}$ and sleep habits. ${ }^{17-23}$

To date, in clinical pediatric practice, in association with pharmacological treatment, ${ }^{24}$ many alternative therapies have been explored and some have shown promise in the treatment of headache symptoms and/or comorbidities in affected children, such as weight loss, ${ }^{25}$ nutraceuticals, ${ }^{26-28}$ sleep hygiene, ${ }^{29,30}$ psychotherapy, and generic psychological interventions. ${ }^{31-33}$

The early clinical descriptions of the personality of adults affected by migraine headache performed by Wolf ${ }^{34}$ included such characteristics as ambitiousness, extreme tidiness, perfectionism, inflexibility, resentment, and aggression. Further studies were conducted on this topic in adulthood, with conflicting results that could be hypothesized as due to the different migraine types, even if they are still unrecognized and not well coded. . $^{35-39}$

About the psychological characteristics in migrainous children, more studies ${ }^{40,41}$ have identified a sort of neurovegetative instability, a tendency to ambition and perfectionism, low levels of self-concept, ${ }^{12}$ and high anxiety levels. Moreover, children with migraine seem to be more anxious, sensitive, deliberate, cautious, fearful, vulnerable to frustration, tidy, and less physically enduring than comparisons. ${ }^{42}$

Conversely, to the best of our knowledge no studies about the temperamental and the characterial dimension aspects in childhood migraine was conducted. Therefore, the aim of the present study was to describe the temperamental and character aspects in a sample of children affected by MoA and their relationship with clinical aspects of MoA such as frequency, duration, and severity of attacks.

\section{Materials and methods Study population}

The study population consisted of 486 children (239 male, 247 female) aged between 7 and 12 years (mean $10.04 \pm 2.53$ years) consecutively referred for MoA to the Clinic for Headache in Developmental Age of the Clinic of Child and Adolescent Neuropsychiatry at the Second University of Naples, to the Unit of Child and Adolescent Neuropsychiatry at the Perugia University, to the Azienda Sanitaria Locale of Terni; to the Department of Psychiatry at the University of Catanzaro, and to the Child Neuropsychiatry at University of Palermo. The diagnosis of MoA was made according to the pediatric criteria of the International Headache Society Classification 2004. ${ }^{43}$

Exclusion criteria were neurological (ie, epilepsy, all types of headache other than MoA) or psychiatric symptoms (attention deficit hyperactivity disorder, depression, behavioral problems), mental retardation (IQ $\leq 70)$, borderline intellectual functioning (IQ ranging from 71 to 84$),{ }^{44,45}$ overweight (body mass index $[\mathrm{BMI}] \geq 85$ th percentile), obesity (BMI $\geq 95$ th percentile), ${ }^{46,47}$ and anticonvulsant or psychoactive drugs administration.

In order to avoid pessimistic or catastrophic answers to the Junior Temperament and Character Inventory: Parent Version (JTCI), mothers affected by anxiety disorder, depression, or psychosis, or in treatment with psychoactive drugs were not enrolled.

Following recruitment, there was a 4-month run-in period to verify migraine characteristics. 
At the end of the run-in, monthly headache frequency and mean headache duration were assessed from daily headache diaries kept by all the children. Headache intensity was assessed on a visual analog scale, as previous reported. ${ }^{26-28}$

The minimum length of headache required for admission in this study was 8 months, with a minimum of four attacks monthly, each lasting for a duration of 1 hour, according to The International Classification of Headache Disorders. 2nd ed (ICHD-II) criteria. ${ }^{43}$

The results were compared with the findings obtained in a sample of 518 healthy controls ( 258 male, 260 female; mean age $9.86 \pm 2.21$ years) randomly selected from schools in the Campania region.

The subjects in both groups were recruited from the same urban area; participants were all Caucasian, and held a middle-class socioeconomic status (between class 2 or class 3 - corresponding to $28,000-55,000$ euros/year to $55,000-75,000$ euros/year, respectively - according to the current Italian economic legislation parameters). All parents gave their written informed consent. The Departmental Ethics Committee approved the study. The study was conducted according to the criteria of the Declaration of Helsinki. ${ }^{48}$

\section{Junior Temperament and Character Inventory-Parent version (JTCl)}

To evaluate the temperamental characteristics of children affected by MoA, the mothers filled out the Italian version of the JTCI. ${ }^{49,50}$ This tool is based on the personality structure as described by Cloninger and reflects the downward extension of the Temperament and Character Inventory (TCI) ${ }^{3,7}$ largely used in adulthood..$^{51}$ The JTCI is a reliable and valid instrument for the assessment of children between the ages of 6 and 16 years. ${ }^{50}$ The JTCI provides a comprehensive inventory of dimensions of temperament (ie, automatic emotional drives) and character (ie, voluntary goals and values) and has good psychometric properties. ${ }^{49} \mathrm{It}$ is comprised of 108 statements that the respondent rates as true or false based on how the child usually acts and feels. The Italian version of JTCI, like other versions of the JTCI, is designed to assess a normative range of behavioral, emotional, and physiologic phenomena, not only psychopathology.

For this study, we assessed the four temperament dimensions of the JTCI, namely NS, HA, RD, and P, and the three character domains: SD, CO, and ST. HA is formulated as the inhibition of behavior by anxiety-provoking stimuli; NS involves the activation of behavior by a desire to explore novelty or complexity as well as excitability by frustration and boredom; RD involves need for social approval and attachment; P involves perseverance of behavior despite frustration and fatigue; SD expresses the individual's competence toward autonomy, reliability, and maturity; $\mathrm{CO}$ is the ability to get along with other people by being tolerant, emphatic, helpful, and forgiving; and ST is a person's ability to identify with nature and the world as a whole as a person seeks to understand what is beyond their individual human existence and is able to sublimate and act altruistically. ${ }^{50}$ Strong development of each of the three character dimensions has been shown to promote health and happiness generally. ${ }^{52}$

Mother-report of child temperament was used for the current investigation. In order to determine the temperamental characteristics of our sample, we defined high levels of each domain by comparing the data derived from our sample with those reported in the JTCI Italian validation criteria. ${ }^{50}$ In this study, the JTCI was administered only to the mother, as the parent who usually spends more time with their children.

\section{Statistical analysis}

In order to compare the demographic characteristics (age and sex) and the JTCI results between MoA children and the controls, Chi-square tests and $t$-tests, where appropriate, were applied. Then, to explore the relationship between JTCI domains and clinical aspects of MoA such as frequency, duration, and severity of attacks, the Spearman rank correlation test was applied. For all statistical analysis $P$-values $<0.05$ were considered to be significant. All data were coded and analyzed using the commercially available STATISTICA 6.0 package for Windows (StatSoft, Inc, Tulsa, OK).

\section{Results}

The two study groups were not significantly different for age $(10.04 \pm 2.53$ years in the MoA group versus $9.86 \pm 2.21$ years in the control group; $P=0.227$ ) or sex (male/female ratio: 239/247 in the MoA group versus $258 / 260$ in the control group; $P=0.892$ ). Among the MoA clinical characteristics, in the MoA group the attacks occurred with a mean frequency of $7.47 \pm 1.65$ attacks per month, a mean duration of $8.47 \pm 0.94$ hours, and a mean intensity of $6.13 \pm 1.39$ according to visual analog scale parameters. The MoA group showed a significantly higher prevalence of HA and $\mathrm{P}$ temperamental domains $(P<0.001)$ and a significantly lower prevalence of SD character trait ( $P=0.023)$ with respect to the control group (Table 1$)$. Moreover, the Spearman rank correlation analysis showed a significant relationship between MoA characteristics and temperamental domains; particularly, high levels of HA and P domains were positively related with frequency $(r=0.636$, 
Table I Comparison between children affected by MoA and typical children on the Junior Temperament and Character Inventory: Parent Version

\begin{tabular}{lllll}
\hline & $\begin{array}{l}\text { MoA } \\
(\mathbf{N}=\mathbf{4 8 6}) \\
(\%)\end{array}$ & $\begin{array}{l}\text { Controls } \\
(\mathbf{N}=\mathbf{5} \text { I8) } \\
(\%)\end{array}$ & $\begin{array}{l}\text { Chi-square } \\
\text { value }\end{array}$ & P-value \\
\hline NS high levels & 37.45 & 43.05 & 3.041 & 0.081 \\
HA high levels & 63.17 & 39.58 & 54.913 & $<0.001$ \\
RD high levels & 42.59 & 47.68 & 3.400 & 0.065 \\
P high levels & 64.61 & 38.03 & 69.814 & $<0.001$ \\
SD high levels & 46.30 & 53.67 & 5.159 & 0.023 \\
C high levels & 51.85 & 57.53 & 3.037 & 0.081 \\
ST high levels & 54.32 & 52.70 & 0.203 & 0.652 \\
\hline
\end{tabular}

Notes: Table I shows the differences in prevalence of high levels in the domains of the Junior Temperament and Character Inventory: Parent Version questionnaire between children affected by MoA and typical developing children (controls). Specifically, according to Cloninger's model, four temperament dimensions (NS, HA, $R D$, and $P$ ) and three higher order character dispositions (SD, C, and ST) were considered. $P$-values $<0.05$ were considered to be statistically significant.

Abbreviations: $\mathrm{C}$, cooperativeness; $\mathrm{HA}$, harm avoidance; MoA, migraine without aura; NS, novelty seeking; P, persistence; RD, reward dependence; SD, selfdirectedness; ST, self-transcendence.

$P<0.001 ; r=0.818, P<0.001$, respectively), duration ( $r=0.135, P=0.002 ; r=0.270, P<0.001$, respectively), and intensity $(r=0.532, P<0.001 ; r=0.707, P<0.001$, respectively) of migraine attacks, while high level of NS and RD domains were negatively related with frequency ( $r=-0.200, P<0.001 ; r=-0.207, P<0.001$, respectively) and intensity $(r=-0.347, P<0.001 ; r=-0.286, P<0.001$, respectively) of migraine attacks. For the character traits, the MoA sample showed a significant negative relationship between high levels of SD and frequency $(r=-0.865$, $P<0.001)$, duration $(r=-0.450, P<0.001)$, and intensity $(r=-0.632, P<0.001)$ of migraine attacks; while the ST domain was significantly related only with frequency and duration of attacks $(r=-0.164, P<0.001 ; r=-0.153$, $P<0.001$, respectively); and the $\mathrm{C}$ domain was related only with frequency of $\mathrm{MoA}(r=-0.201, P<0.001)$.

\section{Discussion}

The main finding of the present study was the presence of peculiar differences in the temperamental and character profiles of MoA children with respect to typical (no migraine) subjects. Our findings about the higher prevalence of the HA $(P<0.001)$ and $\mathrm{P}(P<0.001)$ temperamental domains in MoA children seem to confirm the results of a previous report on temperamental aspects of adults affected by migraine. ${ }^{53}$ In fact, Sánchez-Román et al found higher scores in the HA dimension and all of its subdimensions, and, regarding the character scores, lower scores in the SD domain in adults affected by migraine which is consistent with our pediatric sample. $^{53}$
Specifically, according to Cloninger's model, individuals with high values in HA tend to be cautious, careful, fearful, tense, apprehensive, nervous, timid, doubtful, discouraged, insecure, passive, negativistic, or pessimistic even in situations that do not normally worry other people. Consequently, these individuals tend to be inhibited and shy in most social situations, with low energy level and chronic self-perception of tiredness. Moreover, they need more reassurance and encouragement than most people and are usually sensitive to criticism and punishment. The advantages of high HA scores are the greater care and caution in anticipating possible danger, which leads to careful planning in dangerous situations. ${ }^{6}$ In this light, we could hypothesize that the prevalence of HA in MoA children could be related to the effect of recurrence of migraine attacks as showed by our results about the significant direct relationship between HA score and frequency $(P<0.001)$ and intensity $(P<0.001)$ of attacks.

The recent report about the cerebellar role in the temperamental traits showed that HA scores were negatively associated with white matter and cortex cerebellar volumes, ${ }^{54}$ even if more studies failed to demonstrate a significant reduction of cerebellar volumes in migraine subjects, ${ }^{55}$ although MoA children tend to present an impairment in coordination abilities $^{16}$ that could be considered an indirect sign of cerebellar dysfunction.

The characterological aspects of personality involve individual differences in self-concepts about goals and values, in contrast to the temperaments which involve differences in automatic emotional reactions and habits. Such self-concepts modify the significance or meaning of what is experienced, thus also changing emotional reactions and habits. ${ }^{6}$ Accordingly, individuals with the same temperament may behave differently as a result of character development. According to this definition, the results of the present study showed a reduction in the MoA children of the SD domain SD correlated negatively with frequency, intensity, and duration of attacks; this could pinpoint the role of migraine in the development of different character styles. Recently, overall behavioral disorders have been reported as more common in children who experienced headache than in controls. ${ }^{12,56}$

Conversely, the temperamental characteristics seem to impact and/or influence many aspects of life and can represent a predisposing factor to develop obesity, ${ }^{57-59}$ depressive symptoms ${ }^{60}{ }^{6 x e c u t i v e ~ f u n c t i o n i n g ~ a l t e r a t i o n s, ~},{ }^{61,62}$ and sleep troubles. ${ }^{63-65}$

The main limitation of this study is that no data about the maternal personality aspects and their relationship with the temperamental dimensions of the MoA children were 
collected, even though we excluded mothers with clear psychiatric symptomatology.

Notwithstanding this limitation, our study identified differences in temperamental characteristics in children affected by MoA with respect to comparisons, suggesting the need for this evaluation in order for better psychological pediatric management of children with migraine, with possible consequences and impact on the future outcomes of these subjects.

\section{Acknowledgment}

The authors thank Elda Andriola for having provided materials support.

\section{Disclosure}

The authors report no conflicts of interest in this work.

\section{References}

1. John OP, Robins RW, Pervin LA. Handbook of Personality, Third Edition: Theory and Research. New York: The Guilford Press; 2008.

2. Cloninger CR. A systematic method for clinical description and classification of personality variants. A proposal. Arch Gen Psychiatry. 1987;44(6):573-588.

3. Cloninger CR. The Temperament and Character Inventory (TCI): A Guide to Its Development and Use. St Louis: Washington University, Center for Psychobiology of Personality; 1994.

4. Purper-Ouakil D, Cortese S, Wohl M, et al. Temperament and character dimensions associated with clinical characteristics and treatment outcome in attention-deficit/hyperactivity disorder boys. Compr Psychiatry. 2010;51(3):286-292.

5. Urgesi C, Romanò M, Fornasari L, Brambilla P, Fabbro F. Investigating the development of temperament and character in school-aged children using a self-report measure. Compr Psychiatry. 2012;53(6):875-883.

6. Kose S. A Psychobiological Model of Temperament and Character: TCI. Yeni Symposium: psikiyatri, nöroloji ve davraniş bilimleri dergisi. 2003;41(2):86-97. Available from: http://www.moityca.com.br/pdfs/ Cloninger2003.PDF. Accessed July 10, 2013.

7. Cloninger CR, Svrakic DM, Przybeck TR. A psychobiological model of temperament and character. Arch Gen Psychiatry. 1993;50(12): 975-990.

8. Smith TW, MacKenzie J. Personality and risk of physical illness. Annu Rev Clin Psychol. 2006;2:435-467.

9. Sovio U, King V, Miettunen J, et al. Cloninger's Temperament dimensions, socio-economic and lifestyle factors and metabolic syndrome markers at age 31 years in the Northern Finland Birth Cohort 1966. J Health Psychol. 2007;12(2):371-382.

10. Kernick D, Campbell J. Measuring the impact of headache in children: a critical review of the literature. Cephalalgia. 2009;29(1):3-16.

11. Wöber-Bingöl C. Epidemiology of migraine and headache in children and adolescents. Curr Pain Headache Rep. 2013;17(6):341.

12. Esposito M, Gallai B, Parisi L, et al. Self-concept in childhood migraine. Neuropsychiatr Dis Treat. 2013;9:1061-1066.

13. Esposito M, Gallai B, Parisi L, et al. Maternal stress and childhood migraine: a new perspective on management. Neuropsychiatr Dis Treat. 2013;9:351-355.

14. Carotenuto M, Esposito M, Di Pasquale F, De Stefano S, Santamaria F. Psychological, cognitive and maternal stress assessment in children with primary ciliary dyskinesia. World J Pediatr. In press 2013.

15. Esposito M, Pascotto A, Gallai B, et al. Can headache impair intellectual abilities in children? An observational study. Neuropsychiatr Dis Treat. 2012;8:509-513.
16. Esposito M, Verrotti A, Gimigliano F, et al. Motor coordination impairment and migraine in children: a new comorbidity? Eur $J$ Pediatr. 2012;171(11):1599-1604.

17. Carotenuto M, Guidetti V, Ruju F, Galli F, Tagliente FR, Pascotto A. Headache disorders as risk factors for sleep disturbances in school aged children. J Headache Pain. 2005;6(4):268-270.

18. Vendrame M, Kaleyias J, Valencia I, Legido A, Kothare SV. Polysomnographic findings in children with headaches. Pediatr Neurol. 2008;39(1):6-11.

19. Carotenuto M, Esposito M, Precenzano F, Castaldo L, Roccella M. Cosleeping in childhood migraine. Minerva Pediatr. 2011;63(2): 105-109.

20. Carotenuto M, Esposito M, Pascotto A. Migraine and enuresis in children: an unusual correlation? Med Hypotheses. 2010;75(1):120-122.

21. Esposito M, Gallai B, Parisi L, et al. Primary nocturnal enuresis as a risk factor for sleep disorders: an observational questionnaire-based multicenter study. Neuropsychiatr Dis Treat. 2013;9:437-443.

22. Esposito M, Roccella M, Parisi L, Gallai B, Carotenuto M. Hypersomnia in children affected by migraine without aura: a questionnaire-based case-control study. Neuropsychiatr Dis Treat. 2013;9:289-294.

23. Esposito M, Parisi P, Miano S, Carotenuto M. Migraine and periodic limb movement disorders in sleep in children: a preliminary case-control study. J Headache Pain. 2013;14(1):57.

24. Gallelli L, Avenoso T, Falcone D, et al. Effects of acetaminophen and ibuprofen in children with migraine receiving preventive treatment with magnesium. Headache. 2013. In Press. doi: 10.1111/head.12162.

25. Verrotti A, Agostinelli S, D'Egidio C, et al. Impact of a weight loss program on migraine in obese adolescents. Eur J Neurol. 2013;20(2): 394-397.

26. Esposito M, Ruberto M, Pascotto A, Carotenuto M. Nutraceutical preparations in childhood migraine prophylaxis: effects on headache outcomes including disability and behaviour. Neurol Sci. 2012;33(6): $1365-1368$.

27. Esposito M, Carotenuto M. Ginkgolide B complex efficacy for brief prophylaxis of migraine in school-aged children: an open-label study. Neurol Sci. 2011;32(1):79-81.

28. Carotenuto M, Esposito M. Nutraceuticals safety and efficacy in migraine without aura in a population of children affected by neurofibromatosis type I. Neurol Sci. 2013; doi: 10.1007/s10072-013-1403-z.

29. Bruni O, Galli F, Guidetti V. Sleep hygiene and migraine in children and adolescents. Cephalalgia. 1999;19 Suppl 25:57-59.

30. Carotenuto M, Gallai B, Parisi L, Roccella M, Esposito M. Acupressure therapy for insomnia in adolescents: a polysomnographic study. Neuropsychiatr Dis Treat. 2013;9:157-162.

31. Chopra R, Robert T, Watson DB. Non-pharmacological and pharmacological prevention of episodic migraine and chronic daily headache. WV Med J. 2012;108(3):88-91.

32. Kröner-Herwig B, Gassmann J. Headache disorders in children and adolescents: their association with psychological, behavioral, and socio-environmental factors. Headache. 2012;52(9):1387-1401.

33. Sieberg CB, Huguet A, von Baeyer CL, Seshia S. Psychological interventions for headache in children and adolescents. Can J Neurol Sci. 2012;39(1):26-34.

34. Wolff HG. Personality features and reactions of subjects with migraine. Arch Neurol Psychiatry. 1937;37(4):895-921.

35. Alvarez WC. The migrainous personality and constitution; the essential features of the disease; a study of 500 cases. Am J Med. 1947; 213(1):1-8.

36. Friedman AP. Reflection on the problem of headaches. JAMA. 1964;190(5):445-447.

37. Köhler T, Kosanic S. Are persons with migraine characterized by a high degree of ambition, orderliness, and rigidity? Pain. 1992;48(3): 321-323.

38. Hathaway SR, McKinley JC. Manual of the Minnesota Multiphasic Personality Inventory. Minneapolis: University of Minnesota Press; 1943.

39. Mongini F, Fassino S, Rota E, et al. The temperament and character inventory in women with migraine. $J$ Headache Pain. 2005;6(4):247-249. 
40. Balottin U, Poli PF, Termine C, Molteni S, Galli F. Psychopathological symptoms in child and adolescent migraine and tension-type headache: a meta-analysis. Cephalalgia. 2013;33(2):112-122.

41. Vahlquist B. Migraine in children. Int Arch Allergy Appl Immunol. 1955;7(4-6):348-355.

42. Bille BS. Migraine in school children. A study of the incidence and short-term prognosis, and a clinical, psychological and electroencephalographic comparison between children with migraine and matched controls. Acta Paediatr Suppl. 1962;136:1-151.

43. Headache Classification Subcommittee of the International Headache Society. The International Classification of Headache Disorders. 2nd ed. Cephalalgia. 2004;24 Suppl 1:9-160.

44. Esposito M, Carotenuto M. Intellectual disabilities and power spectra analysis during sleep: a new perspective on borderline intellectual functioning. J Intellect Disabil Res. 2013. doi: 10.1111/jir.12036.

45. Esposito M, Carotenuto M. Borderline intellectual functioning and sleep: the role of cyclic alternating pattern. Neurosci Lett. 2010;19;485(2): 89-93.

46. Carotenuto M, Santoro N, Grandone A, et al. The insulin gene variable number of tandemrepeats (INS VNTR) genotype and sleep disordered breathing in childhood obesity. J Endocrinol Invest. 2009;32(9): $752-755$.

47. Carotenuto M, Bruni O, Santoro N, Del Giudice EM, Perrone L, Pascotto A. Waist circumference predicts the occurrence of sleepdisordered breathing in obese children and adolescents: a questionnairebased study. Sleep Med. 2006;7(4):357-361.

48. World Medical Association. WMA Declaration of Helsinki - Ethical Principles for Medical Research Involving Human Subjects. Seoul: 59th WMA General Assembly; 2008. Available at: http://www.wma. net/en/30publications/10policies/b3/. Accessed April 25, 2013

49. Luby JL, Svrakic DM, McCallum K, Przybeck TR, Cloninger CR. The Junior Temperament and Character Inventory: preliminary validation of a child self-report measure. Psychol Rep. 1999;84(3 Pt 2): 1127-1138.

50. Andriola E, Donfrancesco R, Zaninotto S, et al. The Junior Temperament and Character Inventory: Italian validation of a questionnaire for the measurement of personality from ages 6 to 16 years. Compr Psychiatry. 2012;53(6):884-892.

51. Martinotti G, Mandelli L, Di Nicola M, et al. Psychometric characteristic of the Italian version of the Temperament and Character Inventory revised, personality, psychopathology, and attachment styles. Compr Psychiatry. 2008;49(5):514-522.
52. Cloninger CR, Zohar AH. Personality and the perception of health and happiness. J Affect Disord. 2011;128(1-2):24-32.

53. Sánchez-Román S, Téllez-Zenteno JF, Zermeño-Phols F, et al. Personality in patients with migraine evaluated with the "Temperament and Character Inventory”. J Headache Pain. 2007;8(2):94-104.

54. Laricchiuta D, Petrosini L, Piras F, et al. Linking novelty seeking and harm avoidance personality traits to basal ganglia: volumetry and mean diffusivity. Brain Struct Funct. 2013.

55. Liu J, Zhao L, Li G, et al. Hierarchical alteration of brain structural and functional networks in female migraine sufferers. PLoS ONE. 2012;7(12):e51250.

56. Pavone P, Rizzo R, Conti I, et al. Primary headaches in children: clinical findings on the association with other conditions. Int J Immunopathol Pharmacol. 2012;25(4):1083-1091.

57. Anzman-Frasca S, Stifter CA, Birch LL. Temperament and childhood obesity risk: a review of the literature. J Dev Behav Pediatr. 2012;33(9): $732-745$.

58. Hughes SO, Shewchuk RM. Child temperament, parent emotions, and perceptions of the child's feeding experience. Int J Behav Nutr Phys Act. 2012;9:64.

59. Wu T, Dixon WE, Dalton WT, Tudiver F, Liu X. Joint effects of child temperament and maternal sensitivity on the development of childhood obesity. Matern Child Health J. 2011;15(4):469-477.

60. Garcia D, Kerekes N, Andersson Arntén AC, Archer T. Temperament, character, and adolescents' depressive symptoms: focusing on affect. Depress Res Treat. 2012;2012:925372.

61. Pignatti R, Bernasconi V. Personality, clinical features, and test instructions can affect executive functions in Eating Disorders. Eat Behav. 2013;14(2):233-236.

62. Lahat A, Degnan KA, White LK, et al. Temperamental exuberance and executive function predict propensity for risk taking in childhood. Dev Psychopathol. 2012;24(3):847-856.

63. Hayes MJ, McCoy SK, Fukumizu M, Wellman JD, Dipietro JA. Temperament and Sleep-Wake Behaviors from Infancy to Toddlerhood. Infant Child Dev. 2011;20(5):495-508.

64. Moore M, Slane J, Mindell JA, Burt SA, Klump KL. Sleep problems and temperament in adolescents. Child Care Health Dev. 2011;37(4): 559-562.

65. Ednick M, Cohen AP, McPhail GL, Beebe D, Simakajornboon N, Amin RS. A review of the effects of sleep during the first year of life on cognitive, psychomotor, and temperament development. Sleep. 2009;32(11):1449-1458.
Neuropsychiatric Disease and Treatment

\section{Publish your work in this journal}

Neuropsychiatric Disease and Treatment is an international, peerreviewed journal of clinical therapeutics and pharmacology focusing on concise rapid reporting of clinical or pre-clinical studies on a range of neuropsychiatric and neurological disorders. This journal is indexed on PubMed Central, the 'PsycINFO' database and CAS.

\section{Dovepress}

The manuscript management system is completely online and includes a very quick and fair peer-review system, which is all easy to use. Visit http://www.dovepress.com/testimonials.php to read real quotes from published authors. 